\section{Radioprotective Effect of Arbutin in Megavoltage Therapeutic X-irradiated Mice using Liver Enzymes Assessment}

\author{
Nadi S. ${ }^{1 \oplus}$, Elahi M. ${ }^{2}$, Moradi S. ${ }^{3}$, Banaei A. ${ }^{2,4}$, Ataei Gh.5, \\ Abedi-Firouzjah R. ${ }^{6 *(0)}$
}

\begin{abstract}
Background: Medical use of ionizing radiation has direct/indirect undesirable effects on normal tissues. In this study, the radioprotective effect of arbutin in megavoltage therapeutic $\mathrm{x}$-irradiated mice was investigated using serum alkaline phosphatase (ALP), alanine aminotransferase (ALT), and asparate amniotransferase (AST) activity measurements.

Material and Methods: In this analytical and experimental lab study, sixty mice (12 identical groups) were irradiated with $6 \mathrm{MV}$ x-ray beam (2 and 4 Gy in one fraction). Arbutin concentrations were chosen 50,100, and $200 \mathrm{mg} / \mathrm{kg}$ and injected intraperitoneal 2 hours before irradiation. Samples of peripheral blood cells were collected and serum was separated on the 1, 3, and 7 days post-x-radiation; in addition, the level of ALP, ALT, and AST were measured. Data were analyzed using one-way ANOVA, and Tukey HSD test.

Results: X-radiation ( 2 and 4 Gy) increased the ALT and AST activity levels on the 1,3 , and 7 days post- irradiation, but the ALP level significantly increased on the 1 and 7 days and decreased on the third day compared to the control group $(\mathrm{P}<$ 0.001). ALP, ALT and AST activity levels in " 2 and 4 Gy x irradiation + distilled water" groups were significantly higher than " 2 and 4 Gy irradiation $+50,100$, and 200 $\mathrm{mg} / \mathrm{kg}$ arbutin" groups on the first and seventh day post-irradiation $(\mathrm{P}<0.001)$.

Conclusion: Arbutin is a strong radioprotector for reducing the radiation effect on the whole-body tissues by measuring ALP, ALT and AST enzyme activity levels. Furthermore, the concentration of $50 \mathrm{mg} / \mathrm{kg}$ arbutin showed higher radioprotective effect.
\end{abstract}

Citation: Nadi S, Elahi M, Moradi S, Banaei A, Ataei Gh, Abedi-Firouzjah R. Radioprotective Effect of Arbutin in Megavoltage Therapeutic X-irradiated Mice using Liver Enzymes Assessment. J Biomed Phys Eng. 2019;9(5):533-540. https://doi.org/10.31661/jbpe.v0i0.1199.

Keywords

Arbutin; Liver; Enzymes; Radiation Protection

\section{Introduction}

$\mathrm{I}$ onizing radiation is used for medical diagnosing and treatment. However, this radiation has side effects, it has some benefits in medicine. Radiation therapy (RT) has been reported as one of the important treatment options and approximately $50 \%$ of all patients undergoing RT due to long-term advantages [1,2]. This kind of treatment has direct/ indirect toxic and carcinogenic effects on normal tissues [3, 4].

Non-pharmacological and pharmaceutical strategies are the two main methods for reducing the radiation damage. The non-pharmacological
${ }^{1} \mathrm{MSc}$, Department of Medical Physics Radiobiology and Radiation

Protection, School of

Medicine, Babol Univer-

sity of Medical Sciences,

Babol, Iran

${ }^{2}$ PhD, Medical Physics

Department, Faculty of

medical Sciences, Tar-

biat Modares University,

Tehran, Iran

${ }^{3} \mathrm{MSc}$, Medical Physics

Department, Faculty of

medical Sciences, Tar-

biat Modares University,

Tehran, Iran

${ }^{4} \mathrm{PhD}$, Department of

Radiology, Faculty of

paramedical Sciences,

AJA University of Medical

Sciences, Tehran, Iran

${ }^{5} \mathrm{MSc}$, Department of

Radiology Technology,

Faculty of Paramedical

Sciences, Babol Univer-

sity of Medical Science,

Babol, Iran

${ }^{6} \mathrm{MSc}$, Department of Ra-

diation Sciences, Yasuj

University of Medical

Sciences, Yasuj, Iran

*Corresponding author: R. Abedi-Firouzjah

Department of Radiation

Sciences, Yasuj Univer-

sity of Medical Sciences,

Yasuj, Iran

E-mail: razzaghabedi@

gmail.com

Received: 12 June 2019

Accepted: 7 July 2019 
methods included modification of the radiotherapy technique and method of irradiation, like the volumetric irradiation, using beam shapers, and changing the number of radiation fields $[1,5]$. Although the non-pharmacological strategy can reduce the RT damage, the probability of secondary cancers incidence has been still remarkably high [6].

Pharmaceutical strategies, including radioprotectors and radiosensitizers, as a moderator of free radical damage in the targeted radiotherapy are utilized for reducing toxicity in normal tissues [7]. Radioprotectors are divided into two groups, including natural and chemical agents.

Arbutin or hydroquinone glycoside, is a natural agent [8], that can be found in lots of plants belonging to the Ericaceae and Compositae groups [8,9]. Peduncles, leaves, and bark of Pyrus plants contain certain values of arbutin [8]. Arbutin is a yellow powder soluble in water and alcohols, and the molecular weight is $272.25 \mathrm{~g} / \mathrm{mol}$. The maximum and minimum absorbance spectra of arbutin are 267 and $240 \mathrm{~nm}$, respectively [10].

ALP is an endogenous protein and a factor that can predict the level of cancer metastasis; in addition, it is an easy test yielding quick results [11]. ALP has four types, including placental, intestinal, germ cell, and liver/bone/ kidney ALP [12]. The prognostic role of ALP has been prospected in different types of cancers such as bony metastatic prostate cancer, bony metastatic breast cancer, and clear cell chondrosarcoma of the bone [11, 13, 14]. Mild to moderate elevation of the enzyme caused by free radicals from cell damage can be seen in all types of disorders [15-17]. The deviation and level of ALP have been utilized as an indicator for determining the radiation damage $[3,12,13]$.

Other serum activities (aminotransferases), including ALT and AST can show liver disorders and are reliable sensitive markers of liver diseases [18]. Their levels will increase into the bloodstream when an organ (liver, heart, etc.) is diseased or damaged.

The effectiveness of a radioprotective agent in patients undergoing RT is an important challenge. In a study by Benkovic et al. [3], the effect of propolis and flavonoids as radioprotectors was investigated in gamma-irradiated mice using ALP level assessment method. In another study, Ramadan et al. [18] evaluated the radioprotective effect of silymarin in gamma-irradiated rats in different doses and days by ALP, ALT, and AST levels.

The aim of this study was to investigate the radioprotective effect of arbutin in megavoltage therapeutic $\mathrm{x}$-irradiated mice by measuring liver enzymes, ALP, ALT, and AST activities after 1,3 , and 7 days. In addition, the biocompatibility of the arbutin with the liver enzyme activity was evaluated at three different concentrations.

\section{Material and Methods}

\section{Animal}

In this analytical and experimental lab study, sixty male NMRI mice (6 to 7 weeks old, $25 \pm 5$ gr) were obtained from Iran University of Medical Science (Tehran, Iran). Mice were maintained under controlled conditions, including appropriate temperature $\left(22 \pm 1^{\circ} \mathrm{C}\right)$, humidity, light regime $(12 \mathrm{hr}$. light $/ 12 \mathrm{hr}$. dark), and had free access to a commercial diet.

\section{Chemical}

Pure $(98 \%)$ arbutin powder (Sigma, Germany) was dissolved in distilled water with concentrations of 50,100, and $200 \mathrm{mg} / \mathrm{kg}$ and injected into mice intraperitoneal 2 hours before irradiation.

\section{Irradiation procedure}

Mice were placed in a collective cages made of Plexiglas for whole-body exposure after at least two weeks of acclimatization and conditioning. Mice were exposed by a 6-MV photon beam from an Elekta Compact accelerator 
(Elekta AB, Stockholm, Sweden). The sourceto-skin distance was $100 \mathrm{~cm}$ with a field size of $20 \times 20 \mathrm{~cm}^{2}$. All animals were irradiated with 2 and 4 Gy in one fraction delivered at a dose rate of $200 \mathrm{cGy} / \mathrm{min}$.

\section{Experimental design}

Different concentrations of arbutin were injected to the mice. After two weeks, the animals were divided to twelve groups in separate Plexiglas cage, five mice for each group. The groups were selected as following:

Group 1: "Sham irradiation + distilled water (control)", Group 2: "2 Gy x irradiation + distilled water", Group 3: "4 Gy x irradiation + distilled water", Group 4: "Sham irradiation + 50 mg/kg arbutin", Group 5: "Sham irradiation + $100 \mathrm{mg} / \mathrm{kg}$ arbutin", Group 6: "Sham irradiation + $200 \mathrm{mg} / \mathrm{kg}$ arbutin”, Group 7: "2 Gy x irradiation + $50 \mathrm{mg} / \mathrm{kg}$ arbutin", Group 8: "2 Gy x irradiation + $100 \mathrm{mg} / \mathrm{kg}$ arbutin", Group 9: "2Gy x irradiation + 200 mg/kg arbutin”, Group 10: “4 Gy x irradiation +50 mg/ kg arbutin", Group 11: "4 Gy x irradiation + $100 \mathrm{mg} / \mathrm{kg}$ arbutin", and Group 12: "4 Gy x irradiation $+200 \mathrm{mg} / \mathrm{kg}$ arbutin”.

\section{Blood sampling}

Blood samples were collected from the mice exposed to irradiation and/or arbutin injection after 1, 3, and 7 days and serum samples were separated. The serum level of ALT (IU/L) was estimated according to Kind and King method [19], and serum ALT and AST (U.mL-1) levels were calculated based on the method proposed by Reitman and Frankel [20].

\section{Statistical Analysis}

All measurements were analyzed using SPSS 16 software (SPSS Inc., Chicago, Illinois, US). Multiple comparisons between groups were performed using one-way analysis of variance (ANOVA), and Tukey's test as the post hoc analysis. The level of statistical significance was set at $\mathrm{P}<0.05$.

\section{Results}

According to Figures 1, 2, and 3, ALP, ALT, and AST levels in the "Sham irradiation +50 , 100 , and $200 \mathrm{mg} / \mathrm{kg}$ arbutin" groups were not significantly disturbed in comparison with the control group during 1, 3, and 7 days post-radiation $(\mathrm{P}>0.05)$. The ALP activity level in the

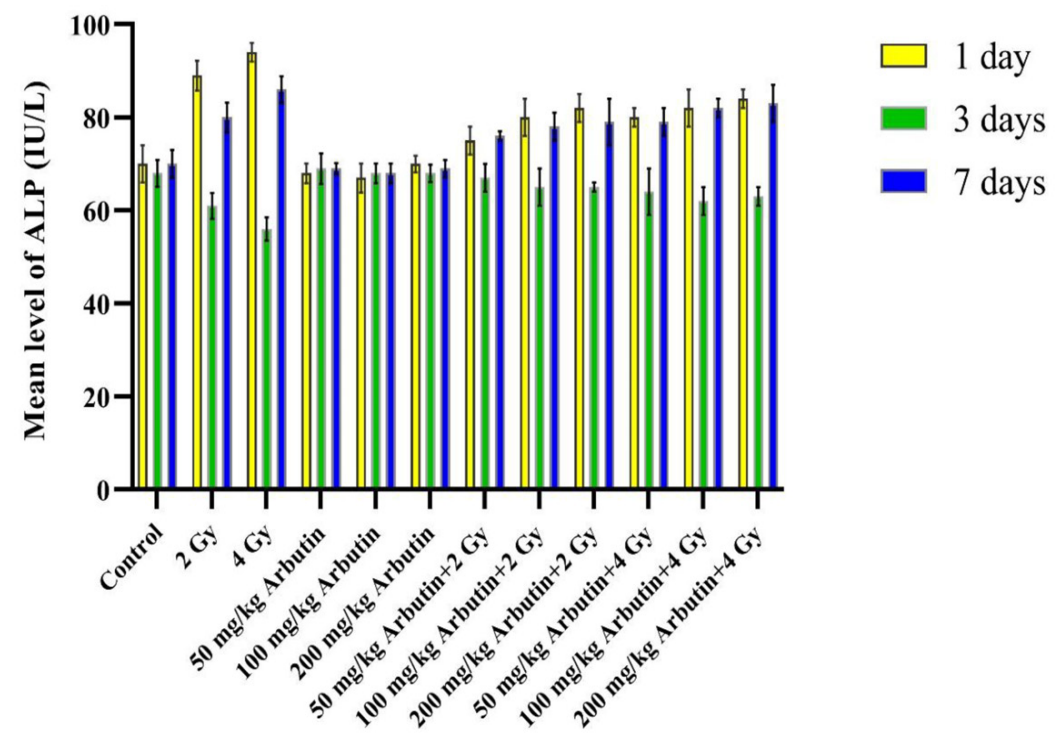

Figure 1: The effectiveness of $x$-irradiation along with various concentrations of arbutin in ALP level on the 1,3 , and 7 days. 


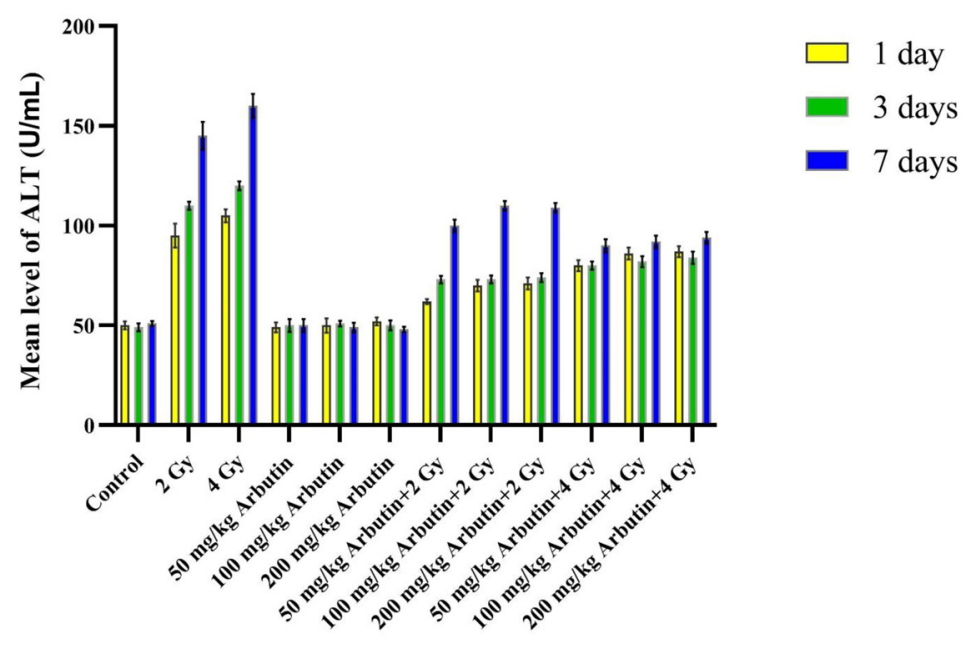

Figure 2: The effectiveness of x-irradiation along with various concentrations of arbutin in ALT level on the 1,3 , and 7 days.

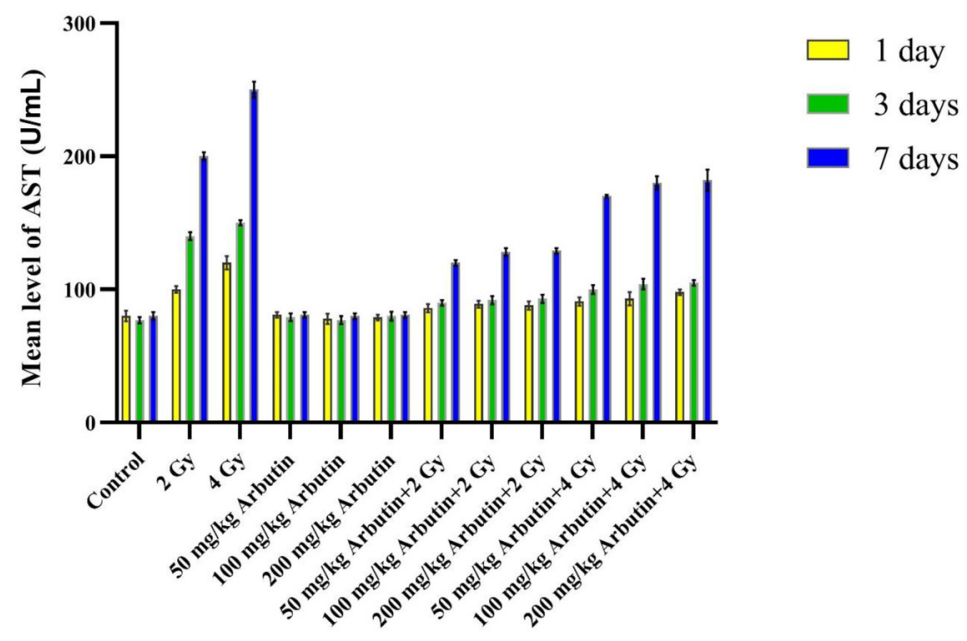

Figure 3: The effectiveness of $x$-irradiation along with various concentrations of arbutin in AST level on the 1,3 , and 7 days.

"2 and 4 Gy x irradiation + distilled water" was significantly higher on the 1 and 7 days, but it was significantly lower on the third day postirradiation compared to the control group and all arbutin concentrations groups $(\mathrm{P}<0.001)$. In addition, significantly higher ALT and AST activity levels were observed in " 2 and 4 Gy $x$ irradiation + distilled water" on the 1,3 , and 7 days post- irradiation respect to the control group and all arbutin concentrations groups $(\mathrm{P}<0.001)$.

ALP level in the " 2 and 4 Gy $x$ irradiation + distilled water" groups was significantly higher on the 1 and 7 days after irradiation in comparison with the " 2 and 4 Gy irradiation + $50 \mathrm{mg} / \mathrm{kg}$ arbutin", "2 and 4 Gy irradiation + $100 \mathrm{mg} / \mathrm{kg}$ arbutin", and "2 and 4 Gy irradiation $+200 \mathrm{mg} / \mathrm{kg}$ arbutin" groups, but it was 
significantly lower on the third day post- irradiation $(\mathrm{P}<0.001)$. After 1,3 , and 7 days postirradiation, ALT and AST levels in " 2 and 4 Gy x irradiation + distilled water" groups were considerably higher than the " 2 and 4 Gy irradiation $+50 \mathrm{mg} / \mathrm{kg}$ arbutin", "2 and 4 Gy irradiation $+100 \mathrm{mg} / \mathrm{kg}$ arbutin", and "2 and $4 \mathrm{~Gy}$ irradiation $+200 \mathrm{mg} / \mathrm{kg}$ arbutin" $(\mathrm{P}<0.001)$.

Statistical analysis showed that ALP enzyme activity in the " 2 Gy irradiation $+50 \mathrm{mg} / \mathrm{kg}$ arbutin" group was notably lower than the " 2 Gy irradiation $+100 \mathrm{mg} / \mathrm{kg}$ arbutin" and "2 Gy irradiation $+200 \mathrm{mg} / \mathrm{kg}$ arbutin" groups on the first and seventh days post- irradiation $(\mathrm{P}<$ $0.05)$, and this variation was considerable on the 1, 3, and 7 days for ALT and AST levels. There were not significant differences in the "2 Gy irradiation + $100 \mathrm{mg} / \mathrm{kg}$ arbutin" compared to the "2Gy irradiation $+200 \mathrm{mg} / \mathrm{kg}$ arbutin" group for ALP, ALT, and AST activity levels $(\mathrm{P}>0.05)$. Furthermore, no remarkable differences were found in ALP, ALT, and AST levels between the " 4 Gy irradiation $+50 \mathrm{mg}$ / $\mathrm{kg}$ arbutin" and "4 Gy irradiation $+100 \mathrm{mg} /$ $\mathrm{kg}$ arbutin" groups $(\mathrm{P}>0.05)$, but there was a significant difference in the "4Gy irradiation + $200 \mathrm{mg} / \mathrm{kg}$ Arbutin" compared with the "4 Gy irradiation $+50 \mathrm{mg} / \mathrm{kg}$ Arbutin" and "4 Gy irradiation $+100 \mathrm{mg} / \mathrm{kg}$ Arbutin” groups.

Figure 4 shows the results concerning ALP,
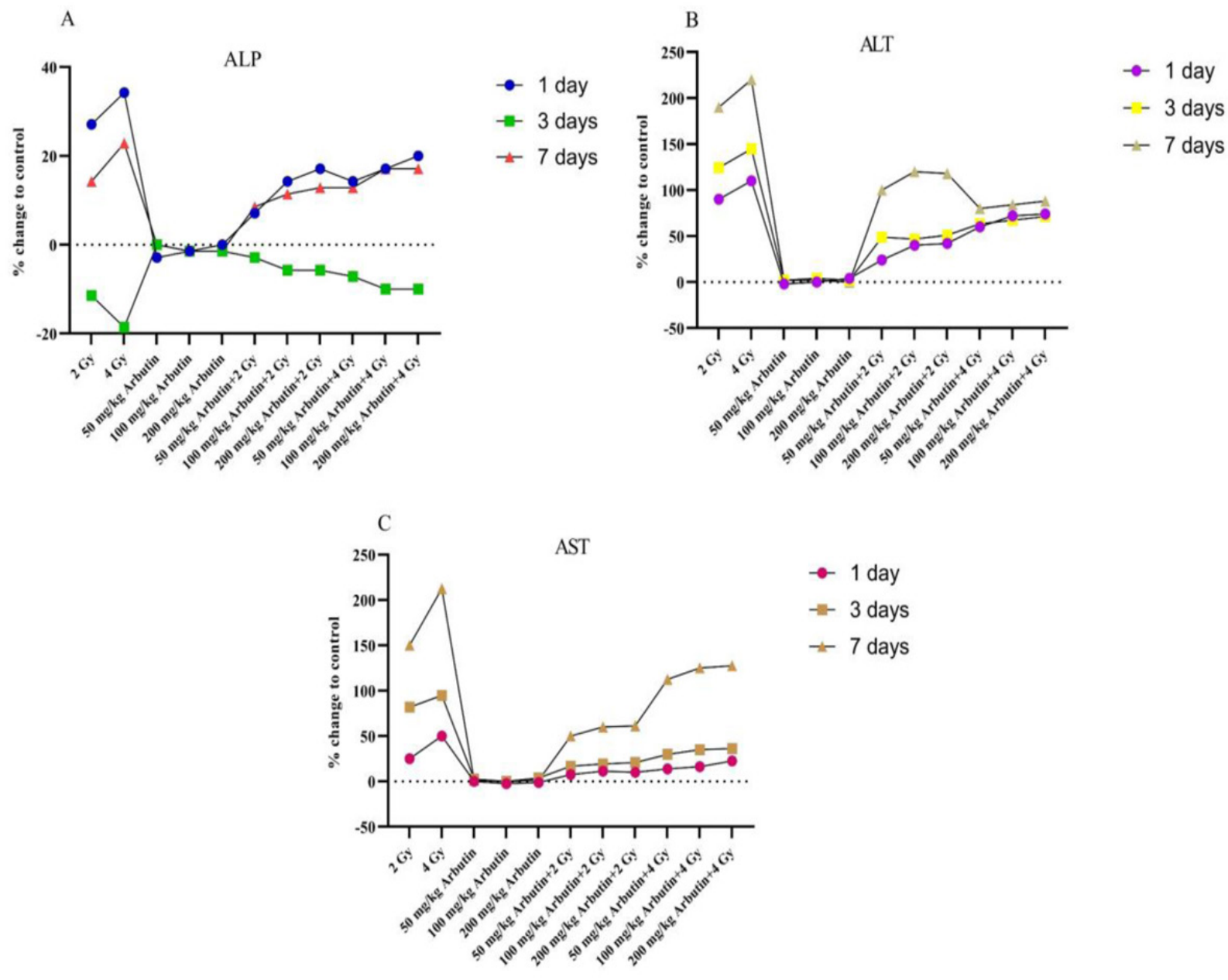

Figure 4: Effects of $x$-irradiation and different concentrations of arbutin at ALP (A), ALT (B), and AST (C) levels with respect to the control group in different days. 
ALT, and AST enzyme levels determined in blood serum of mice compared with the control group. This figure shows clearly the relationship of the enzymes on the first, third, and seventh days compared to the control group.

\section{Discussion}

RT is an important technique for treatment in various malignancies [2]. However, exposure to ionizing radiation during RT leads to undesirable physiological and biochemical changes in humans and animals $[3,4]$. The search for non-toxic selective and effective radioprotector compounds, that preferentially protect normal tissues, is one of the major challenges in radiation protection researches. In a previous study, Nadi et al. [8] showed the protective effect of arbutin in mice bones as a protector of the clastogenic and cytotoxic effects of ionizing radiation using micronuclei method.

The current study aims to detect what extent of arbutin can improve the levels of ALP, ALT, and AST on the 1,3, and 7 days after $\mathrm{x}$-irradiated mice blood serum.

In recent years, a number of serum markers, ALP, AST, and ALT, have been reported to have prognostic value in patients liver, brain, pancreas, heart, kidneys, lungs, etc. [18, 21]. The level of these enzymes will increase into the bloodstream after radiation or diseases [3, $12,13]$. Serum AST level usually rises immediately and reaches a higher level than ALT initially, after hepatocellular injury [21].

In the current study, x-irradiation (2 and 4 Gy) induced an increase in serum ALP activity after 1 and 7 days and a decrease in the third day with respect to the control value (Figure 4). Ramadan et al. [18] showed the same results with gamma-irradiation (3 Gy). Increasing of ALP activity by radiation in blood serum can be attributed to the possible release of this enzyme from various organs associated with the obstruction of the blood stream to the liver and the decreasing of it may be due to the decrease in liver $\mathrm{Mg}^{2+}$ and $\mathrm{Zn}^{2+}$ [18].

In this study, the level of AST and ALT in- creased after 1, 3, and 7 days post-exposure of 2 and 4 Gy x-rays, which is in agreement with Ramadan et al. [18]. The increase in AST and ALT activities, which may be due to the increase in the permeability of cell membranes, facilitates the passage of cytoplasmic enzymes outside the cells regarding the damage of cellular membranes during radiation [22].

After different injections of arbutin, there were not observed any remarkable changes in the level of ALP, ALT, and AST with respect to the control group. Furthermore, we found that arbutin can store ALP, ALT, and AST activity about normal range during megavoltage therapeutic $\mathrm{x}$-irradiated mice. For evaluating the biocompatibility of arbutin with blood serum, measurements were made after 1,3 , and 7 days post- irradiation.

The results showed, whole-body x-irradiation ( 2 or $4 \mathrm{~Gy}$ ) along with arbutin (all three concentrations) induced a significant decrease in ALT and ALS levels compared to the other irradiated groups through the time intervals and it could store ALP level in the normal range on the first, third, and seventh day postirradiation. Benkovic et al. [3] evaluated the propolis and flavonoids as a radioprotectors before gamma whole-body irradiated mice by measuring ALP activity. They indicated that these radioprtectors had protected mice from lethal effects and reduced primary DNA damage in their white blood cells. Ramadan et al. [18] investigated that the silymarin effect as a radioprotective in various doses of gammairradiation ( 3 and $6 \mathrm{~Gy}$ ) induced hepatotoxicity. They reported that silymarin can diminish ALP, ALT, and AST due to its antioxidant effect and the ability to scavenge free radicals after irradiation.

According to our previous study [8], arbutin has a considerable protective and ameliorative effect against radiation and this protective action is related to its antioxidant properties. Therefore, it can sweep free radical, inhibit lipid peroxidation, stabilize plasma membrane, and able to restore the changes of en- 
zyme activities such as ALP, ALT and AST.

Although the effects of three concentrations of arbutin were approximately similar, a minor difference was observed between them. The concentration of $50 \mathrm{mg} / \mathrm{kg}$ arbutin plus 2 Gy x radiation was the best concentration for dropping ALP, ALT and AST level. It is noticeable that in the dose of $2 \mathrm{~Gy}$, the differences between 100 and $200 \mathrm{mg} / \mathrm{kg}$ of arbutin were not significant, and also 50 and $100 \mathrm{mg} / \mathrm{kg}$ for 4 Gy. Moreover, $200 \mathrm{mg} / \mathrm{kg}$ arbutin plus 4 Gy x radiation had no significant lower effect than 50 and $100 \mathrm{mg} / \mathrm{kg}$ plus 4 Gy x radiation.

As future research, it is suggested that other arbutin concentrations as a radioprotector along with $\mathrm{x}$-radiation in different days should be carried out to find the precise optimized level of ALP, ALT, and AST.

\section{Conclusion}

In the current study, the radioprotective effect of arbutin was investigated in megavoltage therapeutic x-irradiated mice. Using ALP, ALT and AST measurements as an indicator of radiation effects, our findings demonstrated that arbutin is a strong radioprotector for reducing the radiation damage. This radioprotective effect might be correlated with the antioxidant and free radical scavenger. There were not any significant differences between the various concentrations of arbutin (50, 100, and $200 \mathrm{mg} / \mathrm{kg}$ ) for storing ALP, ALT and AST levels, however, the concentration of $50 \mathrm{mg} /$ $\mathrm{kg}$ showed higher radioprotective effects.

\section{Acknowledgment}

The authors would like to thank Iran University of Medical science and Radiotherapy Section of Novin Medical Radiation Institute (Tehran, Iran), for their sincere cooperation.

\section{Conflict of Interest}

\section{None}

\section{References}

1. Abdi Goushbolagh N, Abedi Firouzjah R, Ebrahimnejad Gorji K, Khosravanipour M, Moradi S, Banaei A, et al. Estimation of radiation dose-reduction factor for cerium oxide nanoparticles in MRC- 5 human lung fibroblastic cells and MCF-7 breast-cancer cells. Artif Cells Nanomed Biotechnol. 2018;46:S1215-S25. doi: $10.1080 / 21691401.2018 .1536062$. PubMed PMID: 30481078.

2. Firouzjah RA, Banaei A, Farhood B, Bakhshandeh M. Dosimetric Comparison of Four Different Techniques for Supraclavicular Irradiation in 3D-conformal Radiotherapy of Breast Cancer. Health Phys. 2019;116:631-6. doi: 10.1097/ HP.0000000000000991. PubMed PMID: 30608247.

3. Benkovic V, Orsolic N, Knezevic AH, Ramic S, Dikic D, Basic I, et al. Evaluation of the radioprotective effects of propolis and flavonoids in gamma-irradiated mice: the alkaline comet assay study. Biol Pharm Bull. 2008;31:167-72. doi: 10.1248/bpb.31.167. PubMed PMID: 18175964.

4. Karbownik M, Reiter RJ. Antioxidative effects of melatonin in protection against cellular damage caused by ionizing radiation. Proc Soc Exp Biol Med. 2000;225:9-22. doi: 10.1046/j.15251373.2000.22502.x. PubMed PMID: 10998194.

5. Bertelsen A, Hansen CR, Johansen J, Brink C. Single Arc Volumetric Modulated Arc Therapy of head and neck cancer. Radiother Oncol. 2010;95:142-8. doi: 10.1016/j.radonc.2010.01.011. PubMed PMID: 20188427.

6. Jin T, Song T, Deng S, Wang K. Radiation-induced secondary malignancy in prostate cancer: a systematic review and meta-analysis. Urol Int. 2014;93:279-88. doi: 10.1159/000356115. PubMed PMID: 25139441.

7. Velpula N, Ugrappa S, Kodangal S. A role of radioprotective agents in cancer therapeutics: a review. Int J Basic Clin Pharmacol. 2013;2:677-82. doi: 10.5455/2319-2003.ijbcp20131203.

8. Nadi S, Monfared AS, Mozdarani H, Mahmodzade A, Pouramir M. Effects of Arbutin on Radiation-Induced Micronuclei in Mice Bone Marrow Cells and Its Definite Dose Reduction Factor. Iran J Med Sci. 2016;41:180-5. PubMed PMID: 27217601; PubMed Central PMCID: PMCPMC4876295.

9. Lubsandorzhieva P, Zhigzhitov B, Dargaeva T, Bazarova ZG, Nagaslaeva L. Chromatospectrophotometric determination of arbutin in the leaves ofBergenia crassifolia (L.) Fritsch. Pharmaceutical Chemistry Journal. 2000;34:261-4. doi: 10.1007/ bf02524636.

10. Couteau C, Coiffard LJ. Photostability determination of arbutin, a vegetable whitening agent. Farmaco. 2000;55:410-3. doi: 10.1016/s0014827x(00)00049-5 . PubMed PMID: 10983289. 
11. Jin Y, Yuan MQ, Chen JQ, Zhang YP. Serum alkaline phosphatase predicts survival outcomes in patients with skeletal metastatic nasopharyngeal carcinoma. Clinics (Sao Paulo). 2015;70:264-72. doi: 10.6061/ clinics/2015(04)08. PubMed PMID: 26017793; PubMed Central PMCID: PMCPMC4449461.

12. Sharma U, Pal D, Prasad R. Alkaline phosphatase: an overview. Indian J Clin Biochem. 2014;29:26978. doi: 10.1007/s12291-013-0408-y. PubMed PMID: 24966474; PubMed Central PMCID: PMCPMC4062654.

13. He S, Wang Y, Peng H, Yang L, Chen H, Liang S, et al. Pretreatment Alkaline Phosphatase and Epstein-Barr Virus DNA Predict Poor Prognosis and Response to Salvage Radiotherapy in Patients with Nasopharyngeal Carcinoma and Metachronous Bone-Only Metastasis. J Cancer. 2017;8:417-24. doi: 10.7150/jca.17310. PubMed PMID: 28261343; PubMed Central PMCID: PMCPMC5332893.

14. Li G, Gao J, Tao YL, Xu BQ, Tu ZW, Liu ZG, et al. Increased pretreatment levels of serum LDH and ALP as poor prognostic factors for nasopharyngeal carcinoma. Chin J Cancer. 2012;31:197-206. doi: 10.5732/cjc.011.10283. PubMed PMID: 22237040; PubMed Central PMCID: PMCPMC3777475.

15. Rosen E, Sabel AL, Brinton JT, Catanach B, Gaudiani JL, Mehler PS. Liver dysfunction in patients with severe anorexia nervosa. Int J Eat Disord. 2016;49:151-8. doi: 10.1002/eat.22436. PubMed PMID: 26346046.

16. Sun J, Zhao J, Bao X, Wang Q, Yang X. Alkaline Phosphatase Assay Based on the Chromogenic Interaction of Diethanolamine with 4-Aminophenol.
Anal Chem. 2018;90:6339-45. doi: 10.1021/acs. analchem.8b01371. PubMed PMID: 29683655.

17. Beydilli H, Yilmaz N, Cetin ES, Topal Y, Celik OI, Sahin C, et al. Evaluation of the protective effect of silibinin against diazinon induced hepatotoxicity and free-radical damage in rat liver. Iran Red Crescent Med J. 2015;17:e25310. doi: 10.5812/ ircmj.17(4)2015.25310. PubMed PMID: 26023342; PubMed Central PMCID: PMCPMC4443388.

18. Ramadan LA, Roushdy HM, Abu Senna GM, Amin NE, El-Deshw OA. Radioprotective effect of silymarin against radiation induced hepatotoxicity. Pharmacol Res. 2002;45:447-54. doi: 10.1006/phrs.2002.0990 . PubMed PMID: 12162944.

19. Kind D, King E. Practical clinical biochemistry 1. In: Varley H, Gownlock AH, Bell M, editors. Practical clinical biochemistry. 5th ed. London: William Heinemann Medical Books Ltd. 1954. p. 892.

20. Reitman S, Frankel S. A colorimetric method for the determination of serum glutamic oxalacetic and glutamic pyruvic transaminases. Am J Clin Pathol. 1957;28:56-63. doi: 10.1093/ajcp/28.1.56. PubMed PMID: 13458125.

21. Kim WR, Flamm SL, Di Bisceglie AM, Bodenheimer HC. Public Policy Committee of the American Association for the Study of Liver D. Serum activity of alanine aminotransferase (ALT) as an indicator of health and disease. Hepatology. 2008;47:1363-70. doi: 10.1002/hep.22109. PubMed PMID: 18366115.

22. Khamis F, Roushdy M. Synergistic radioprotective action of imidazole and serotonin on serum and liver enzymes in rats. Arab Journal of Nuclear Sciences and Applications. 1991;24:19-36. 